\title{
In vitro Evaluating the Influence of Grape Seed Polyphenol Extract on the Digestibility of Macronutrients
}

\author{
Jianmei Yu, Yang Mi and Shuang Ji \\ Food and Nutritional Sciences Program, Department of Family and Consumer Sciences, North Carolina A\&T State University. \\ Greensboro NC 27411, USA
}

\begin{abstract}
Interaction between dietary polyphenol and proteins including digestive enzymes may result in reduced digestibility of food macronutrients, thus lowering absorption of nutrients that contributing to high energy accumulation in human body. The objective of this study was to investigate the effect of grape seed polyphenol extract (GSPE) on the digestibility of starch, food lipid and food protein by digestive enzymes such as $\alpha$-amylase, lipase, pepsin and trypsin. The digestion of each substrate was conducted at the optimal $\mathrm{pH}$ and temperature of specific enzyme. Bread containing different amount of grape pomace was used as a real food model and its digestion was conducted under simulated digestion condition. Concentrations of reducing sugar, fatty acid and amino acids in enzyme digested mixtures were determined as indicators of starch, lipid and protein digestions, respectively. Results indicate that GSPE significantly inhibited the digestion of starch, cooking oil and casein, but did not inhibit digestion of whey protein and egg white protein. Instead, the digestion of egg white and whey protein by trypsin was moderately enhanced in the presence of GSPE. However, under simulated human digestion condition, the grape pomace in the bread significantly reduced the digestibility of bread starch and protein.
\end{abstract}

Key words: Grape seed polyphenol extract, grape pomace, macronutrient, bread, digestibility, simulated digestion.

\section{Introduction}

Obesity rates increased $82 \%$ globally and $100 \%$ in the Middle Eastern countries in since 1990. In 2014, more than $13 \%$ of world adults population were obese and $39 \%$ of adults aged 18 years and over were overweight [1]. More than one-third $(34.9 \%$ or 78.6 million) of U.S. adults are obese [2]. Obesity is a major independent risk factor for developing the disease, and more than $90 \%$ of type 2 diabetics are overweight or obese. Raised BMI is a major risk factor for noncommunicable diseases such as cardiovascular diseases (mainly heart disease and stroke), type-2 diabetes, musculoskeletal disorders (especially osteoarthritis - a highly disabling degenerative disease of the joints) and some cancers (endometrial, breast, and colon) [3]. The health burden from high body mass indexes now exceeds that due to hunger [4]. Although

Corresponding author: Jianmei Yu, Ph.D., research scientist, research field: food and nutritional sciences. many factors contribute to the obesity rate increase, diet is one of the major contributing factors. High calorie foods intake and less dietary fiber contribute to weight gain. Among the multiple risk factors underling the incidence and progression of obesity, diet is the main modifiable factor [5-6].

Major food components contributing to energy intake are carbohydrates (starch, disaccharides and monosaccharide), fat and protein [7]. Each of these components is essential to health but over consumption resulted in extra energy accumulation. From nutrition point of view, starch, disaccharides (sucrose, maltose and lactose), fat and protein must be digested and converted into simple sugar, fatty acids and amino acids before they can be absorbed through the intestinal wall. Reduced digestibility of these nutrients should result in reduced nutrient absorption which will be important for population who generally consume too much carbohydrates and fat. Polyphenols may play an important role in this aspect. 
Some polyphenols have been reported to have potential as weight control agents. For example, tea catechins were found to attenuate the development of obesity and fatty liver in mice fed a high fat diet [8], and boost fat oxidation in humans [9]. Chronic administration of green tea decoction (GTD) in rat fed high-fat diet reduced body weight gain, circulating triglycerides and cholesterol and improved glucose tolerance in rat model [10]. It was also reported that grape seed extract reduced food intake in rats and energy intake in human [11].

High polyphenol diets have been reported to inhibit the activities of gastric enzymes [12]. A range of berry polyphenols (e.g. flavonols, anthocyanidins, ellagitannins and proanthocyanidins) can inhibit protease activities at levels which could affect protein digestion in the gastrointestinal tract [13]. Polyphenol extracts of both red and white grape pomace selectively and significantly inhibits intestinal $\alpha$-glucosidase and suppresses postprandial hyperglycemia in diabetic mice [14]. Polyphenols also affect sugar digestion and absorption [15]. These particular effects are unlikely to occur with regular Western human diets, which are characterized by a much lower polyphenol intake [16]. Many studies regarding the protein-polyphenol interaction have also been reported [17-20].

However, the effects of a mixture of polyphenols from grape pomace, the by-products of grapes generated during wine making, on the digestibility of food protein and lipid are rarely reported. In this study, the inhibitory effects of grape seed polyphenol extract GSPE on the in vitro digestibility of starch, food lipid (cooking oil) and some food proteins were evaluated. Bread was used as a real food model to study the influence of addition of grape pomace on the digestibility of starch and protein under simulated digestion condition. The reason of selecting bread as a food model is that bread is the most consumed food product worldwide and it can serve as an excellent vehicle to deliver the health benefits of grape pomace polyphenol to consumers. The effect of GP in bread on lipid digestion was not tested in this study because of the very low lipid content of bread.

\section{Materials and Methods}

\subsection{Materials}

Grape pomace (GP) was obtained from two wineries located in North Carolina, USA. $\alpha$-amylase from a genetically modified strain of Bacillus licheniformis with activity of 17,400 unit/mg was purchased from ANKOM Technology (Macedon, NY); Pepsin from porcine gastric mucosa (837 Unit/mg protein, \% protein $=15.8)$ and lipase $(87 \mathrm{unit} / \mathrm{mg}$ solid $)$ were purchased from Sigma Aldrich (St Louis, MO); and Trypsin from bovine pancrease $(\geq 12,100 \mathrm{unit} / \mathrm{mg}$ protein) were purchased from Fisher Chemical (Fairlawn, NJ). Enzyme subtracts include corn starch and casein soy protein isolate egg white and whey protein were purchased from Fisher Scientific (Suwanee, GA). Chemical reagents includes Folin-Ciocalteu reagent (Sigma-Aldrich, Co., St. Louis. MO), dinitrosalicylic (DNS) Acid Reagent, potassium sodium tartrate, ninhydrin reagent solution (Fisher Scientific, Atlanta, NC) and amino acid standards leucine and proline (MP Biomedicals, Solon, $\mathrm{OH}$ ).

\subsection{Preparationo of Grape Seed Polyphenol Extract (GSPE)}

Cabernet Sauvignon pomace was the source used for producing GSPE. The pomaces from Muscadine Noble, Muscadine Carlos, Cabernet Franc and Cabernet Sauvignon grapes were used for bread making. They were all obtained from two wineries located in North Carolina, USA. After drying in a vacuum oven overnight, the seeds were separated manually from peels and stems, then ground into powder. GSPE was extracted from Cabernet Sauvignon grape seeds using $70 \%$ ethanol. After removing ethanol by rotary evaporator, and then purified using the method described by [21]. The total polyphenol concentrations of purified extracts were determined by Folin-Ciocalteu micro-method using gallic acid as 
standard and expressed as mg gallic acid/mL [22]. The amount of GSPE added to different reaction systems were calculated according to the polyphenol concentration of GSPE and the final polyphenol concentration of the reaction system.

\subsection{Enzymatic Hydrolysis of Corn Starch and Total Reducing Sugar Determination}

2.3.1 Preparation of Corn Starch Solution (1\%, w/v)

One gram $(1.00 \mathrm{~g})$ of corn starch (company, city State) suspended in $80 \mathrm{~mL}$ of DI water in a beaker, stirred and heated to nearly boiling on hot plate stir to let starch completely gelatinize and dissolve. After cooling to room temperature, the starch solution was transferred to $100 \mathrm{~mL}$ volumetric flask and the beaker was rinsed with DI water 3 times. The rinses were added to the flask to bring the total volume to $100 \mathrm{~mL}$.

\subsubsection{Enzymatic Hydrolysis of Starch}

The starch solution was distributed into a set of 6 test tubes, each $10 \mathrm{~mL}$. The precalculated amount of GSPE solution was added to the final polyphenol concentration of $0,0.02,0.04,0.06,0.08$ and 0.1 $\mathrm{mg} / \mathrm{mL}$. The $\alpha$-amylase was then added to the mixture to $8.7 \mathrm{U} / \mathrm{mL}$. The tubes were then capped and incubated at $37{ }^{\circ} \mathrm{C}$ for $30 \mathrm{~min}$ to liquefy starch. When the liquefaction process was completed, the $\mathrm{pH}$ of starch solution was adjusted to 4.7 with $1 \mathrm{~N}$ HCL to inactivate $\alpha$-amylase. The starch hydrolysis experiment was conducted in triplicate.

\subsubsection{Reducing Sugar Determination}

The digestion of starch by alph-amylase produces glucose and maltose which are all reducing sugars. Therefore, total reducing sugar concentration in the digested starch solution was used as indicator of starch digestibility. The reducing sugar content of liquefied starch solution was determined by dinitrosalicylic (DNS) colorimetric method using glucose solutions as standards [23]. The analysis was conducted in triplicate. The glucose concentration in the starch hydrolysate was calculated using the calibration equation/standard curve developed using a set of glucose solutions.
2.4 Hydrolysis of Vegetable Oil by Lipase and Total Fatty Acid Determination

\subsubsection{Enzymatic Hydrolysis of Food Lipid}

Vegetable oil purchased from a local grocery store (Greensboro, NC, USA) was digested with lipase from porcine pancrease (Sigma-Aldrich, St. Louis, $87 \mathrm{U} / \mathrm{mg}$ solid) according to the procedure described by Serri and colleagues [24]. Briefly, a $250 \mathrm{~mL}$ conical flask was initially filled with $3 \mathrm{~g}$ of cooking oil and $30 \mathrm{~mL}$ of iso-octane solvent. A $30 \mathrm{~mL}$ of phosphate buffer solution, pH 7.5 (unless otherwise stated) was added into the conical flask so that the ratio of oil to aqueous (buffer solution) is 0.1 . The precalculated amount of GSPE solution was added to the final GPE concentration of $0,0.02,0.04,0.06,0.08$ and 0.1 $\mathrm{mg} / \mathrm{mL}$. To start the reaction, $0.3 \mathrm{~g}$ lipase $(8.74 \mathrm{U} / \mathrm{g}$ oil) was added to flask and the mixtures were agitated in the orbital shaker at $45^{\circ} \mathrm{C}$ for $30 \mathrm{~min}$. The mixture formed two layers. Samples were withdrawn from the oil layer for total fatty acid analysis. The lipid hydrolysis experiment was conducted in triplicate.

2.4.2 Quantification of Total Fatty Acid in Digested Vegetable Oil

Total fatty acid in the hydrolyzed oil was used as indicator to evaluate the degree of lipid hydrolysis due to the action of lipase. The fatty acid was determined by titration of the oil phase samples with $0.1 \mathrm{M}$ sodium hydroxide $(\mathrm{NaOH})$. To each samples, $5 \mathrm{~mL}$ of the oil phase was dissolved in $5 \mathrm{~mL}$ ethanol: diethyl ether $(1: 1, \mathrm{v} / \mathrm{v})$ then titrated with $0.1 \mathrm{M} \mathrm{NaOH}$ in the presence of Phenolphthalein indicator. The amount of $0.1 \mathrm{M} \mathrm{NaOH}$ required to neutralize the acid was recorded. The fatty acid concentration was expressed as millimole/g oil. A blank titration was done using oil sample that did not go through digestion procedure for adjustment of free fatty existed in the original oil.

\subsection{Hydrolysis of Food Proteins by Simulated Gastric Fluid (SGF)}

\subsubsection{Gastric Digestion of Food Proteins}

This is to simulate the protein digestion in the 
stomach under strong acidic condition. SGF was $0.2 \%$ $\mathrm{NaCl}$ in $0.1 \mathrm{~N} \mathrm{HCL}$ without. Protein solutions $(1 \%)$ of casein, egg white, soy protein isolate and whey protein were prepared by dissolving the proteins in GSF (pH 1.5). The GSPE was then added to a set of each protein solutions to the concentration of $0,0.02,0.04,0.06$, 0.08 and $0.10 \mathrm{mg} / \mathrm{mL}$. Pepsin (Sigma-Aldrich, St Louis, $\mathrm{MO}, 243 \mathrm{U} / \mathrm{mg}$ protein, $36 \%$ protein) was added to each tube to $1.3 \mathrm{mg} / \mathrm{mL}(5.2 \mathrm{U} / \mathrm{mL})$. After mixing, samples were incubated at $37{ }^{\circ} \mathrm{C}$ for $1 \mathrm{~h}$, then adjusted to $\mathrm{pH} 8.0$ using $6 \mathrm{~N}$ HCL to inactivate pepsin. The protein hydrolysis experiment was conducted in triplicate.

\subsubsection{Quantification of Amino Acid Concentration}

Total amino acid content released due to protein hydrolysis was used as indicator of protein digestibility by gastric fluid. The total amino acid concentration was determined by Ninhydrin colorimetric method using leucine as standard [25]. Briefly, enzyme treated samples were diluted with $\mathrm{pH} 7.1$ phosphate buffer, and $1.5 \mathrm{~mL}$ of diluted sample was mixed with $0.3 \mathrm{~mL}$ of ninhydrin solution in test tubes. The tube was then loosely capped and heated in $95{ }^{\circ} \mathrm{C}$ water bath for 7 min. After cooling to room temperature in a cold water bath, the absorbance of reaction mixture was recorded using a spectrophotometer at $570 \mathrm{~nm}$. The amino acid concentration was calculated according to calibration equation developed using leucine as the standard, and expressed millimole/L. The protein hydrolysis experiment was conducted in triplicate.

\subsection{Enzymatic Hydrolysis of Protein Using Trypsin}

The hydrolysis of food proteins by trypsin was conducted at $\mathrm{pH}$ 7.8-8.0 to reflect the $\mathrm{pH}$ of food digestion in the small intestine. Protein solutions (1\%) were prepared with $\mathrm{pH} 8.0$ phosphate buffer. A set of capped test tubes were filled with a single protein solution (10 mL/tube). Precalculated volume of GSPE was then mixed with protein solutions to the GPE concentration of $0,0.2,0.4,0.6,0.8$ and $1.0 \mathrm{mg} / 10 \mathrm{~mL}$. Trypsin powder was then added to each tube
$(1 \mathrm{mg} / \mathrm{mL})$, gently mixed, and then incubated at $37{ }^{\circ} \mathrm{C}$ for $60 \mathrm{~min}$. after incubation, the enzyme was inactivated by merging the tube in a $95{ }^{\circ} \mathrm{C}$ water bath for $15 \mathrm{~min}$. The total amino acid released due to trypsin hydrolysis was determined by Ninhydrin colorimetric method using leucine as standard as described above. The hydrolysis experiment was conducted in triplicate. Sample contains $0 \%$ GSPE was used as control.

\subsection{Simulated Digestion of Bread Containing Grape Pomace}

To test the impact of polyphenol on the digestibility of starch and protein in food matrix, bread model was used. Bread samples were formulated with All Purpose wheat flour (Gold) and powdered grape pomace. Briefly, 5 and $10 \%$ of flour were replaced by grape pomace without changing other ingredients such as water, salt, sugar, yeast and shortening. The formulated dough was baked at $400{ }^{\circ} \mathrm{C}$ for $25 \mathrm{~min}$ and then cooled to room temperature on a rack. The bread was sliced and crust was removed. The inside part of bead was vacuum dried at $70{ }^{\circ} \mathrm{C}$ overnight, and then ground into powder. The bread without grape pomace was used as control.

Two grams of each dry bread sample was mixed with $8 \mathrm{~mL}$ of alpha amylase solution $(8.7 \mathrm{U} / \mathrm{mL}, \mathrm{pH} 5.8-6)$ in water bath shaker at $37^{\circ} \mathrm{C}$ for $5 \mathrm{~min}$. After adjusting to $\mathrm{pH} 2.0$ with concentrated HCL, $5 \mathrm{~mL}$ of SGF containing pepsin $38.87 \mathrm{U} / \mathrm{mL}$ pepsin $(1 \mathrm{mg} / 3 \mathrm{~mL})$ was added and samples were incubated in water bath shaker at low speed for $1 \mathrm{~h}$ in the water bath shaker. The samples were adjusted $\mathrm{pH}$ to $7.8-8$ with $10 \mathrm{~N}$ $\mathrm{NaOH}$, and trypsin $(1 \mathrm{mg} / \mathrm{mL})$ powder was added to each sample to $9 \mathrm{mg} / \mathrm{g}$ bread (equivalent to $12,100 \mathrm{u} / \mathrm{g}$ bread), and then incubated in the water bath shaker for $1 \mathrm{~h}$. After the digestion was completed, The $\mathrm{pH}$ of samples were adjusted to 11 using $10 \mathrm{~N} \mathrm{NaOH}$ was added to inactivate enzymes. Samples were then centrifuged at $3,000 \mathrm{~g}$ for $15 \mathrm{~min}$. Volumes of supernatant were recorded and the precipitates were discarded. Glucose and amino acid concentrations of 
supernatants were determined as described in 2.3 and 2.5 .

\section{Results and Discussions}

\subsection{Effect of GSPE on the Digestion of Food Starch}

Starch is one of the most important dietary carbohydrates. Most dietary carbohydrate is digested in the upper gastrointestinal tract to monosaccharides by carbohydrase such as $\alpha$-amylase and glycosidase. The digestibility of starch by $\alpha$-amylase in the presence of GPE was evaluated by total reducing sugar production.

Fig. 1 shows that the production of reducing sugar decreased linearly with increasing concentration of GPE $(\mathrm{R} 2=0.98)$. This indicates that the digestibility of starch decreases is negatively associated with GSPE content in the diet. The reduced digestibility of corn starch should be caused by inhibitory effect of GSPE on $\alpha$-amylase activity [14]. Their digestion, absorption and metabolism may be influenced by dietary polyphenols and their metabolites [25]. This function is very important in reducing sugar absorption for people who regularly consume large amount starch-based foods such as bread, cake and pasta because many studies have proven the direct relationship between sugar intake and obesity [26].

\subsection{The Effect of GPPE on the Enzymatic Digestion of Food Lipid}

The effect of GSPE on the enzymatic digestion of food lipid (vegetable oil) was evaluated by the release of free fatty acids. Fig. 2 shows that the hydrolysis of food lipid by lipase was inhibited slightly by GSPE under the experimental condition. When GSP concentration in the lipid was $0.0-0.4 \mathrm{mg} / 10 \mathrm{~mL}$, the production of fatty acid decreased with increasing GSP concentration near linearly or exponentially. This indicates that the activity of lipase was greatly inhibited. This is in agreement with the findings of [27] that berry polyphenols significantly reduced the activity of lipase. Strangely, when GSP concentration increased to 0.8 $\mathrm{mg} / 10 \mathrm{~mL}$, fatty acid concentration in the hydrolysis mixture increased again in this study. This might be caused by experimental error.

\subsection{The Effect of GSPE on the Enzymatic Digestion of Food Proteins}

Because the final digestion products of proteins that can be absorbed in human digestion system are amino acids (AA), the digestibility of protein by pepsin and trypsin in the presence of GSPE was evaluated by total amino acid concentration in the digestion mixture.

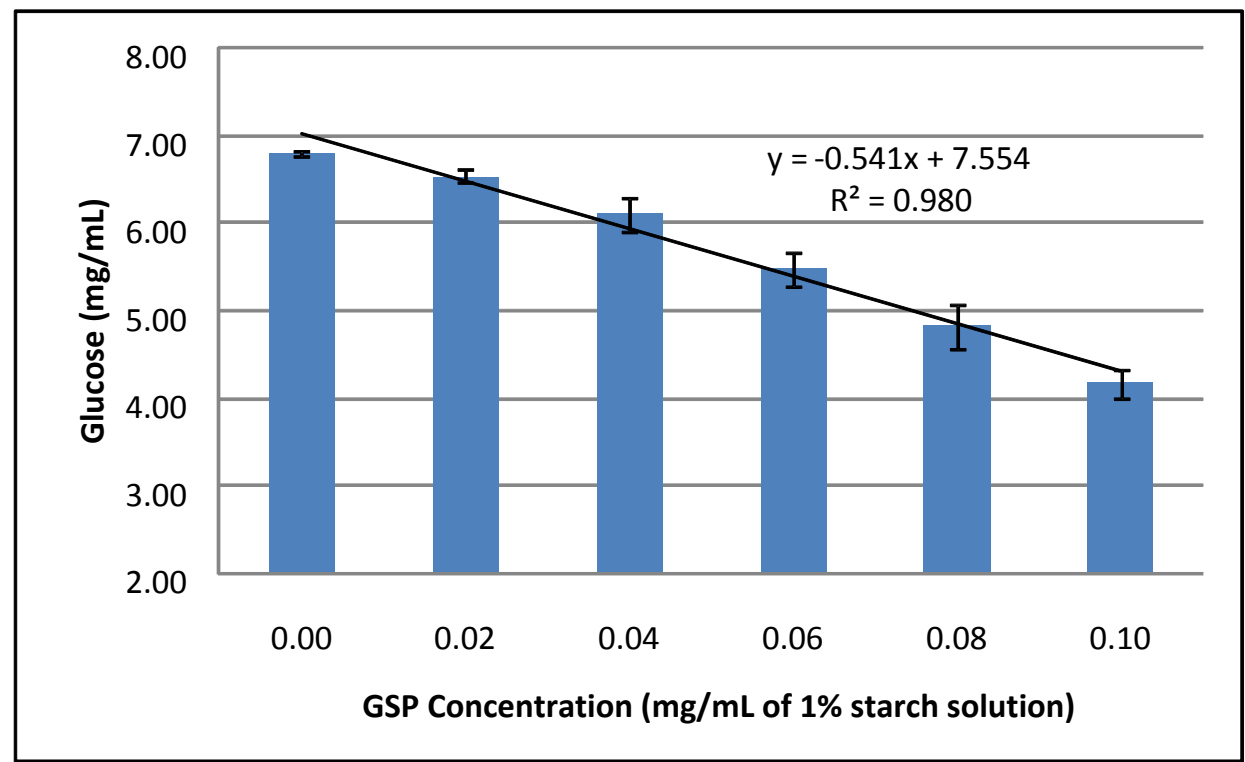

Fig. 1 Effects of GSE concentration on the enzymatic hydrolysis of corn starch (Starch concentration: 1\%; Enzyme: alpha-amylase, 17,400 U/mL, amount added: $87 \mathrm{U} / \mathrm{mL}$ starch solution). 


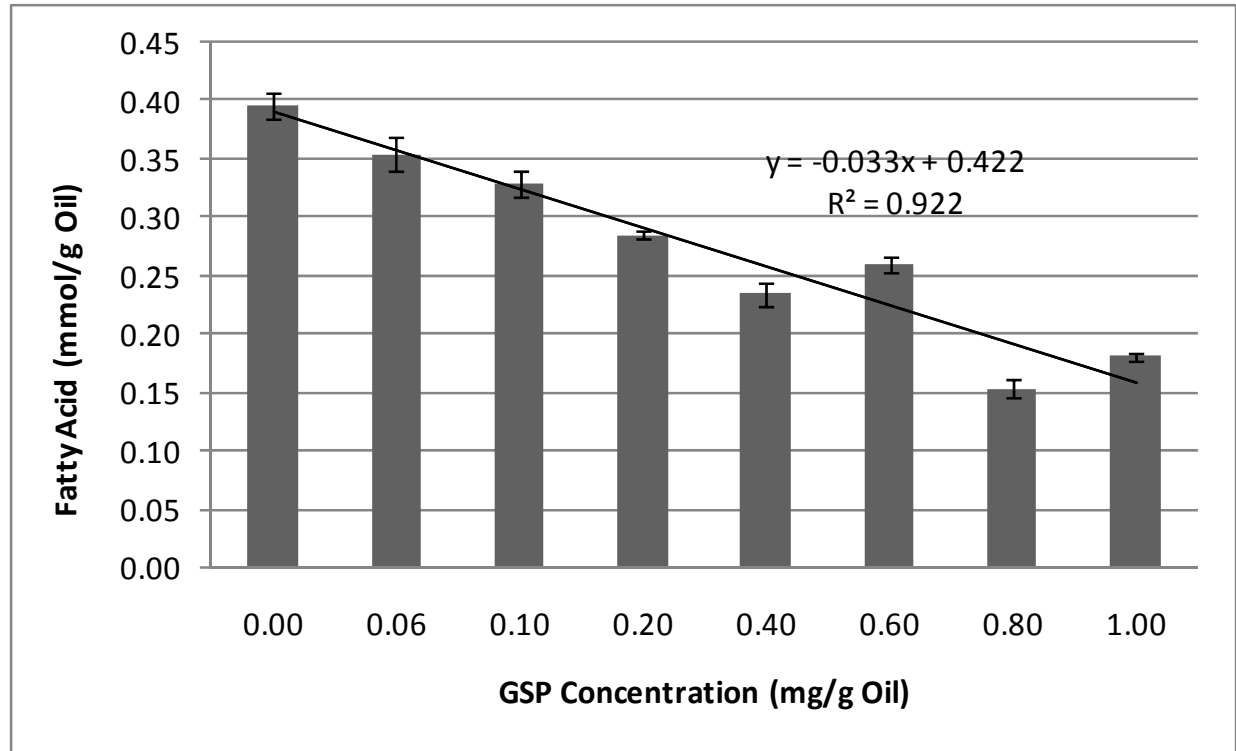

Fig. 2 Effects of GSP concentration on the enzymatic hydrolysis of food lipid (Enzyme: lipase from bovine pancrease, activity $87 \mathrm{U} / \mathrm{mg}$ solid, amount added: $8.74 \mathrm{U} / \mathrm{g}$ oil).

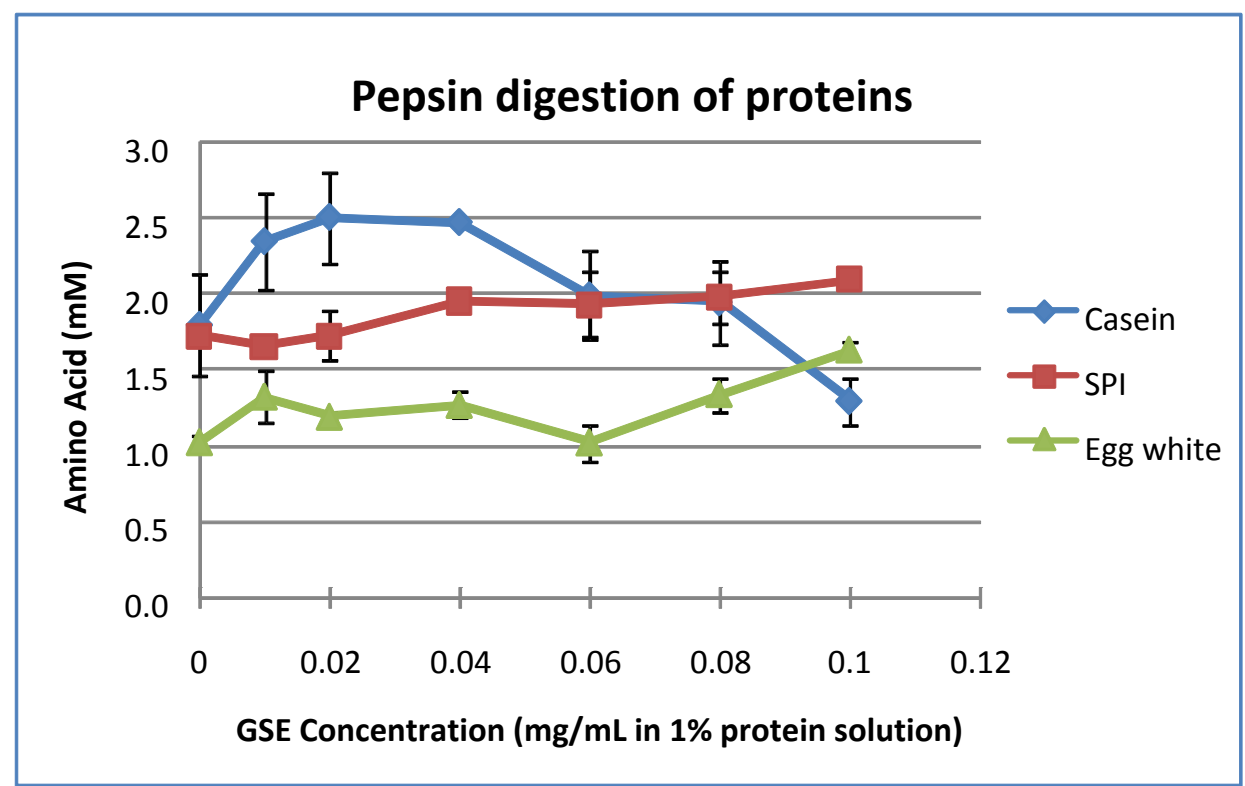

Fig. 3 Effects of grape seed polyphenol on pepsin digestion food proteins. (protein concentration: 1\%; pH 1.5; pepsin from porcine gastric mucosa $837 \mathrm{U} / \mathrm{mg}$ protein), amount added: $100 \mathrm{mg} / 30 \mathrm{~mL}$ ).

In the case of pepsin digestion of food proteins, Fig. 3 shows that the total AA concentration of pepsin digested casein solution increased with increasing GSP concentration until GSP concentration reached 0.04 $\mathrm{mg} / \mathrm{mL}$; above $0.04 \mathrm{mg} / \mathrm{mL}$, AA concentration decreased with GSP concentration. Interestingly, the AA concentration of SPI and egg white protein digesta increased gradually with increasing GSP concentration (Fig. 3). The results indicate that GSPE inhibited the digestion of casein by pepsin, but not SPI and egg white protein. Which suggests the enzymatic activity of pepsin might not be inhibited. The reduced digestibility of casein might be caused by the strong complexation of casein with grape seed polyphenols at some cleave sites of pepsin which makes hydrolysis at these sites unavailable. The SPI and egg white protein might not form strong complex with GSP at the cleave site of pepsin. In addition, under high acidic condition, the 
effect of grape seed polyphenol on the activity of pepsin may not be very strong because acid hydrolysis might dominate the digestion.

In the case of trypsin digestion of food proteins, Fig. 4 shows that the AA concentration decrease with increasing concentration of GSP in casein and SPI solutions, whereas AA concentration increased with increasing GSP concentration in egg white and whey protein solutions. This indicates that the trypsin digestions of casein and SPI were inhibited by GSP, but the trypsin digestion of whey protein and egg white protein were accelerated by GSPE. Because the type and concentration of polyphenol and protease used in the all digestion experiments were the same, the difference in the effects of GSP on digestibility of different protein should be caused by the interactions between GSP and different proteins. The result implicates that the interactions of GSP with casein and SPI were stronger than the interactions between GSE and whey/egg white protein. Therefore, the method used for evaluating the inhibitory effects of GSP on the digestion of food proteins should consider both the inhibition of GSE on the protease and interactions between GSE and food proteins. Development of a better and reliable method is necessary for the study of protein digestibility in the presence of food polyphenols.

\subsection{Effects of GSPE on Starch and Protein in Grape Pomace Fortified Bread}

Because the composition and structure of real food in more complex, the impact of GSP on the digestion of food components in real food matrix may be different from the digestion of individual component alone by a single enzyme. Therefore, bread was used as a real food model to evaluate the effect of GSP on the starch and protein digestion. The grape pomace (GP) powder was used as source of polyphenols. Under simulated human digestion condition, the inclusion of GP in the bread formula significantly reduced the digestibility of bread starch and protein as indicated by the reduced release of reducing sugar and amino acids in the digested samples (Figs. 5 and 6). Regardless the cultivar of grape, the higher the GP content in the bread, the lower the reducing sugar content in the digested bread mixture (Fig. 5), indicating the digestibility of

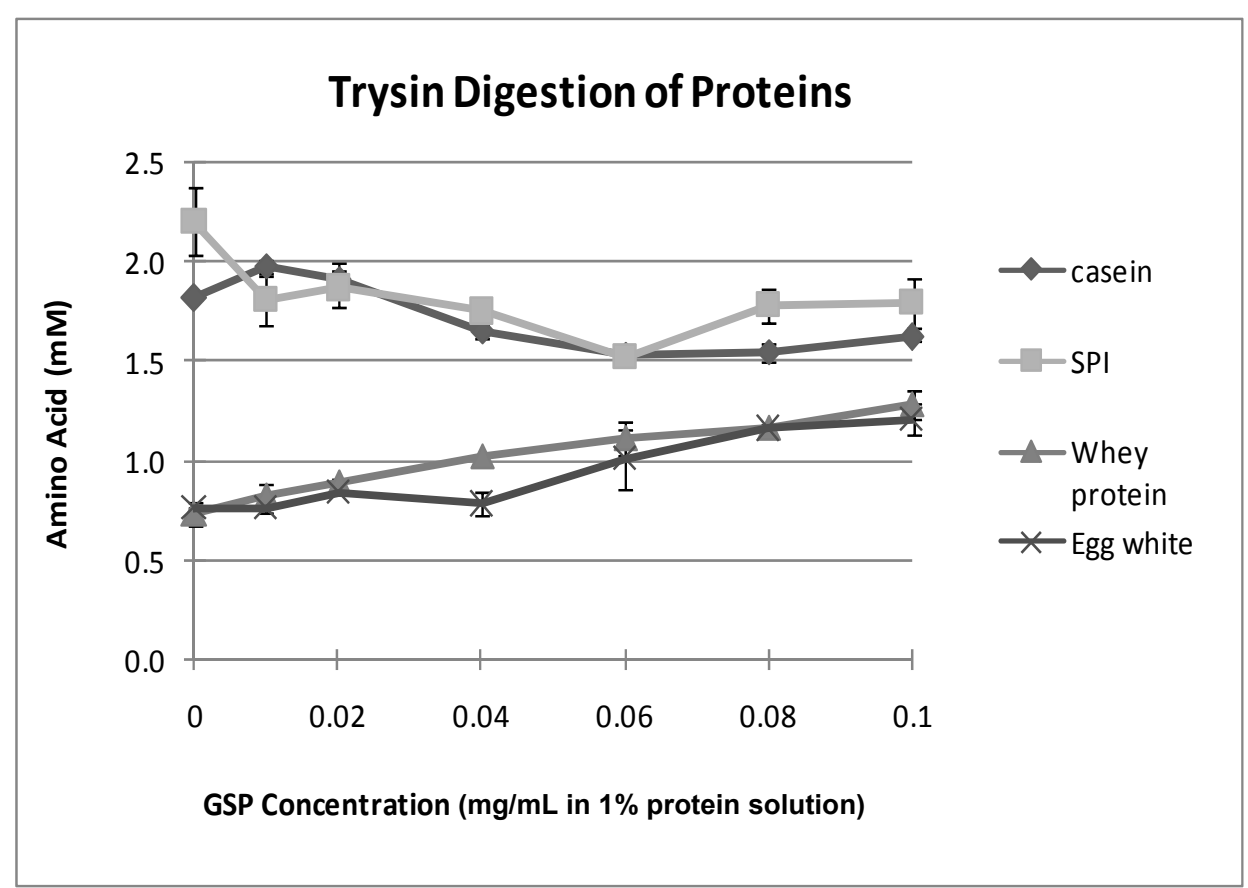

Fig. 4 Effects of grape seed polyphenol extract on the trypsin digestion of food proteins (protein concentration: 1\%; pH 8.0; Trypsin from bovine pancreas ( $\geq 12,100 \mathrm{unit} / \mathrm{mg}$ protein), amount added: $1 \mathrm{mg} / \mathrm{mL}$ ). 


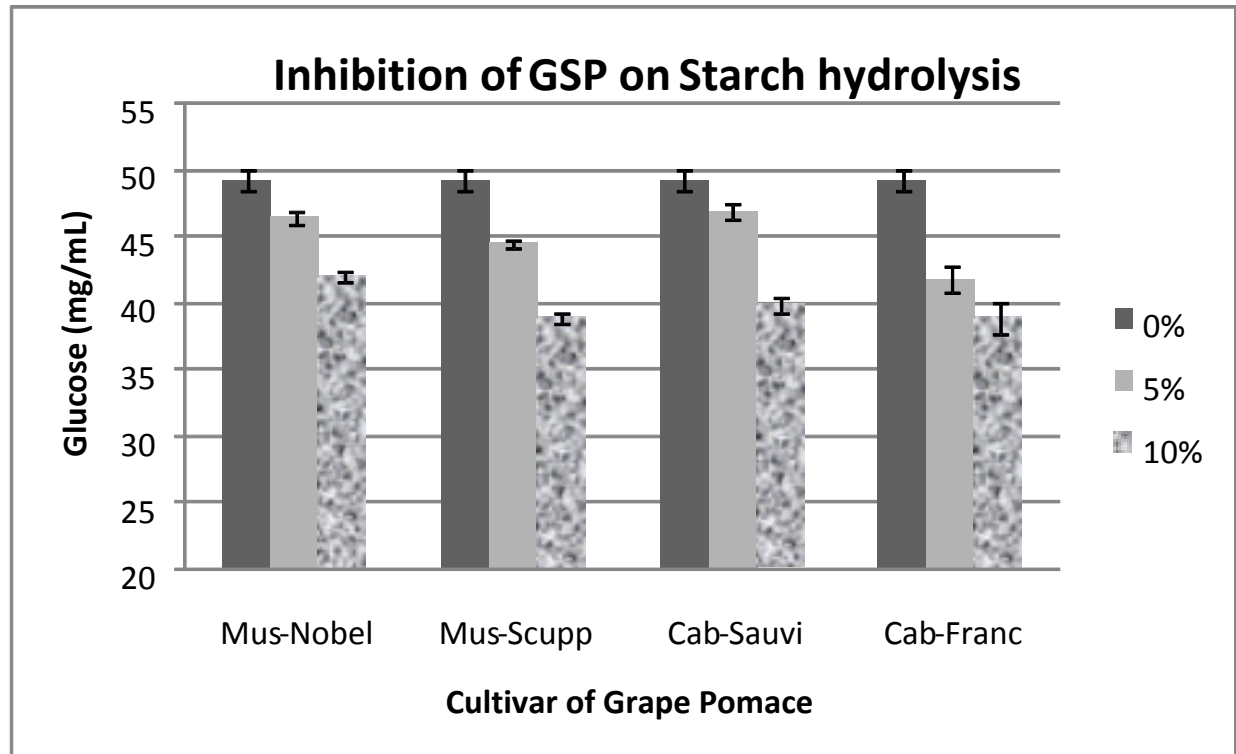

Fig. 5 Effects of grape pomace (GP) addition in bread on the digestibility of starch under simulated digestion condition. (Mus-Nobel: Muscadine Noble, Mus-Scupp: Muscadine Scuppernong, Cab-Sauvi: Cabernet Sauvignon, Cab-Franc: Cabernet Franc).

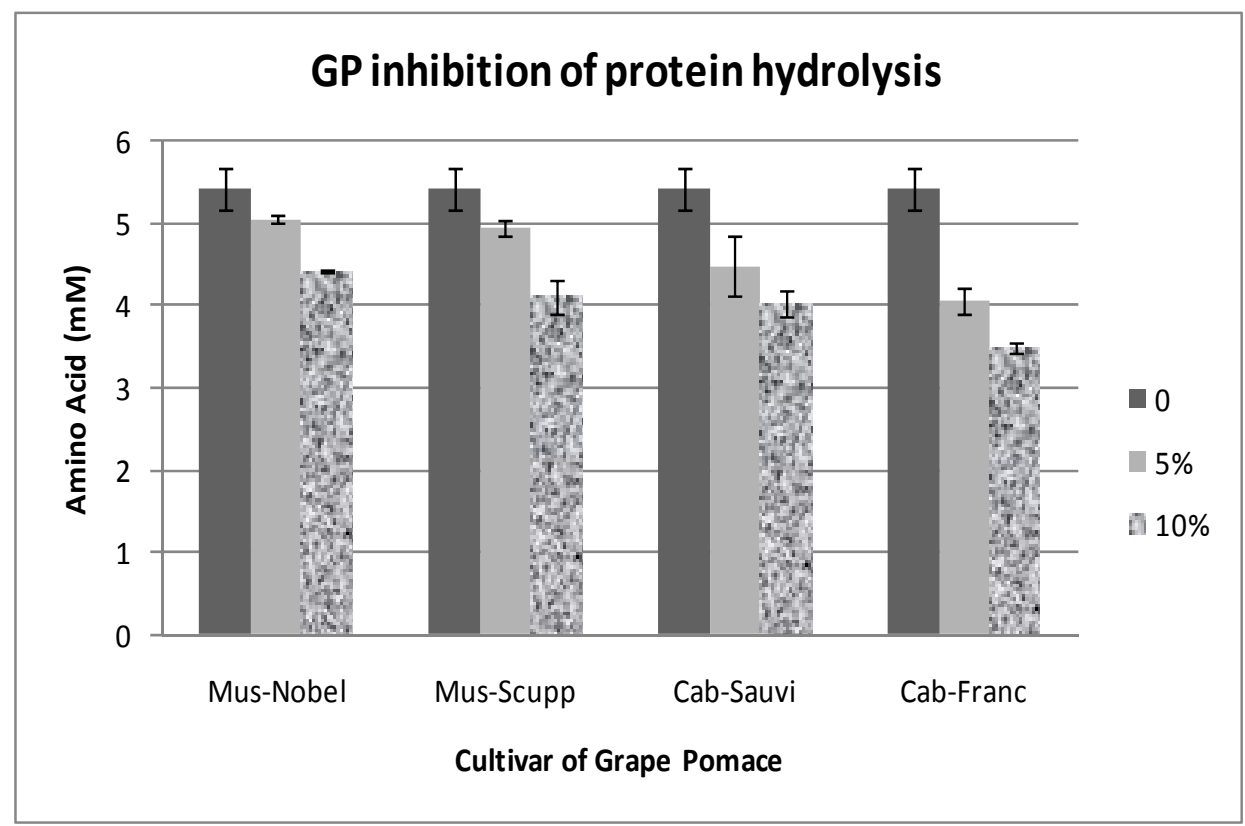

Fig. 6 Effects of grape pomace (GP) addition in bread on the digestibility of protein under simulated digestion condition. (Mus-Nobel: Muscadine Noble, Mus-Scupp: Muscadine Scuppernong, Cab-Sauvi: Cabernet Sauvignon, Cab-Franc: Cabernet Franc).

bread starch decreased as GP content in the bread increasing. However, the digestibility of bread protein did not show GP dose dependent manner (Fig. 6). Adding $5 \%$ of Cabernet Sauvignon pomace significantly reduced the digestibility of bread protein, but increasing the GP content to $10 \%$ did not further reduced the protein digestibility.
This is expected according to single enzyme digestion results discussed above because high GP content in the bread means high polyphenol concentration. In addition, the non-extractable polyphenols and dietary fiber in GP may also affect the digestion of food protein. The results are also consistent with that reported by other researchers. When increasing amount of unripe banana 
flour added in the cookies, the rapidly digestible starch decreased and the slowly digestible starch increased [28].

\section{Conclusions}

The results of this study demonstrate that the presence of GSP strongly inhibited the digestion of food starch and lipid. The digestibility of starch and lipid decreased with GSP in dose dependent manner. This is very important in reducing energy absorption for people who regularly consume foods rich in starch and fat. The effects of GSP on the digestion of food protein are more complicated and vary with types of proteins. The mechanisms of GSP inhibiting the digestion of macronutrients may include the inhibition of digestive enzyme activity and the interaction between the macronutrients and polyphenol molecules which form complex compounds and make the enzyme cleaving site unavailable. The impacts of GSP on human nutrition include two different aspects. On one hand, the reduced digestibility of energy dense macronutrients such as starch and fat will benefit diabetic, obese and overweight people which have been a huge burden to health care system all over the world. On the other hand, the interaction of polyphenol-nutrient may reduce absorption of essential nutrients for growth and maintenance of health. This is undesirable for growing children and people who suffer from malnutrition. This study provides important information about the impact of GSE on the in vitro digestibility of major food nutrients. In vivo study is needed to further evaluate the overall impact of consuming food rich in GSP on the weight gain and general health of target population, for example, the obese population.

\section{Acknowledgments}

This study is financially supported by a grant awarded by National Institute of Food and Agriculture. Grant number: 2011-38821-30906.

\section{References}

[1] WHO (World Health Organization) 2015. World Health
Organization. Obesity and over weigh. Fact sheet $\mathrm{N}^{\circ} 311$. http://www.who.int/mediacentre/factsheets/fs311/en/.

[2] Ogden, C. L., Carroll, M. D., Kit, B. K., and Flegal, K. M. 2014. "Prevalence of Childhood and Adult Obesity in the United States, 2011-2012." The Journal of American Medical Association 311 (8): 806-14. doi: 10.1001/jama.2014.732.

[3] WHO (World Health Organization) 2013. World Health Organization. Obesity and Overweight Fact Sheer. Accessed from http://www.who.int/dietphysicalactivity/media/en/gsfs_ob esity.pdf October 2013.

[4] Finkelstein, E. A., Trogdon, J. G., Cohen, J. W., and Dietz, W. 2013. "Annual Medical Spending Attributable to Obesity: Payer-and Service-specific Estimates." Molecular Nutrition and Food Research 57 (1): 48-57. doi: 10.1002/mnfr.201200511.

[5] Ello-Martin, J. A., Ledikwe, J. H., and Rolls, B. J. 2005. "The Influence of Food Portion Size and Energy Density on Energy Intake: Implications for Weight Management." American Journal of Clinical Nutrition 82: 236S-41S.

[6] Duncan, S., Duncan, E. K., Fernandes, R. A., Buonani, C., Bastos, K. N. D., and Segatto, A. F. M., et al. 2011. "Modifiable Risk Factors for Overweight and Obesity in Children and Adolescents from São Paulo, Brazil." BMC Public Health 11: 585. http://www.biomedcentral.com/1471-2458/11/585.

[7] FAO (Food and Agricultural Organization) 2003. Food Energy-Methods of Analysis and Conversion Factors. Rome, Italy.

[8] Bose, M., Lambert, J. D., Ju, J., Reuhl, K. R., Sue, A., Shapses, S. A., and Yang, C. S. 2008. "The Major Green Tea Polyphenol, (-)-epigallocatechin-3-gallate, Inhibits Obesity, Metabolic Syndrome, and Fatty Liver Disease in High-fat-fed mice." Journal of Nutrition 138: 1677-83.

[9] Venables, M. C., Julston, C. J., Cox, H. R., and Jeukendrup, A. E. 2008. "Green Tea Extract Ingestion, Fat Oxidation, and Glucose Tolerance in Healthy Humans." American Journal of Clinical Nutrtion 87 (3): 778-84.

[10] Snoussi, C., Ducroc, R., Hamdaoui, M. H., Dhaouadi, K., Abaidi, H., and Cluzeaud, F., et al. 2014. "Green Tea Decoction Improves Glucose Tolerance and Reduces Weight Gain of Rats Fed Normal and High-fat Diet." Journal of Nutritional Biochemistry 25 (5): 557-64. doi: 10.1016/j.jnutbio.2014.01.006.

[11] Vogels, N., Nijs, I. M. T., and Westerterp-Plantenga, M. S. 2004. "The Effect of Grape-seed Extract on 24 h Energy Intake in Humans." European Journal of Clinical Nutrition 58 (4): 667-73.

[12] Santos-Buelga, C., and Scalbert, A. 2000. "Proanthocyanidins and Tannin-like Compounds: Nature, Occurrence, Dietary Intake and Effects on Nutrition and 
Health." Journal of Science of Food and Agriculture 80: 1094-117.

[13] Medougall, G. J., and Stewart, D. 2005. "The Inhibitory Effects of Berry Polyphenols on Digestive Enzymes." Biofactors 34 (1): 189-95.

[14] Hoggan, S., Zhang, L., Li, J., Sun, S., Canning, C., and Zhou, K. 2010. “Antioxidant Rich Grape Pomace Extract Suppresses Postprandial Hyperglycemia in Diabetic Mice by Specifically Inhibiting Alpha-glucosidase.” Nutrition and Metabolism 7: 71.

[15] Williamson, G. 2013. "Possible Effects of Dietary Polyphenols on Sugar Absorption and Digestion." Molecular Nutrition and Food Research 57: 48-57.

[16] Arts, I. C. W., and Hollman, P. C. H. 2005. "Polyphenols and Disease Risk in Epidemiologic Studies." American Journal of Clinical Nutrition 81: 317S-25S.

[17] Siebert, K. J., Troukhanova, N. V., and Lynn, P. Y. 1999. "Nature of Polyphenol-Protein Interactions." Journal of Agricultural and Food Chemistry 44: 80-5.

[18] de Freitas, V., Carvalho, E., and Mateus, N. 2003. "Study of Carbohydrate Influence on Protein-tannin Aggregation by Nephelometry." Food Chemistry 81: 503-9.

[19] Fraziera, R. A., Deaville, E. R., Greenc, R. J., Stringanob, E., Willoughbyd, I., Plante, J., and Mueller-Harvey, I. 2010. "Interactions of Tea Tannins and Condensed Tannins with Proteins." Journal of Pharmaceutical and Biomedical Analysis 51: 490-5.

[20] Bandyopadhyay, P., Ghosh, A. K., and Ghosh, C. 2012. "Recent developments on Polyphenol-protein Interactions: Effects on Tea and Coffee Taste, Antioxidant Properties and the Digestive System." Food and Functions 3 (6): 592-605.

[21] Yu, J., Ahmedna, M., and Goktepe, I. 2005. "Effects of Processing Methods and Extraction Solvents on Concentration and Antioxidant Activity of Peanut Skin
Phenolics." Food Chemistry 90: 199-206.

[22] Singleton, V. L., Orthofer, R., and Lamuela-Raventós, R. M. 1999. "Analysis of Total Phenols and Other Oxidation Substrates and Antioxidants by Means of Folin-Ciocalteu Reagent." Methods in Enzymology 299: 152-78.

[23] Gusakov, A. V., Kondratyeva, E. G., and Sinitsyn, A. P. 2011. "Comparison of Two Methods for Assaying Reducing Sugars in the Determination of Carbohydrase Activities." International Journal of Analytical Chemistry: 1-4. doi: $10.1155 / 2011 / 283658$.

[24] Serri, N. A., Kamarudin, A. H., and Abdul Rahaman, S. N. 2008. "Preliminary Studies for Production of Fatty Acids from Hydrolysis of Cooking Palm Oil using C. rugosa Lipase." Journal of Physical Science 19 (1): 79-88.

[25] Friedman, M. 2004. "Applications of the Ninhydrin Reaction for Analysis of Amino Acids, Peptides, and Proteins to Agricultural and Biomedical Sciences." Journal of Agricultural and Food Chemistry 52: 385-406.

[26] Bahadoran, Z., Mirmiran, P., and Azizi, F. 2013. "Dietary Polyphenols as Potential Nutraceuticals Inmanagement of Diabetes: a Review." Journal of Diabetes \& Metabolic Disorders 12: 43.

[27] Drewnowski, A. 2007. "The Real Contribution of Added Sugars and Fats to Obesity." Epidemiology Review 29: 160-71. doi: 10.1093/epirev/mxm011.

[28] Grussu, D., Stewart, D., and McDougall, G. J. 2011. "Berry Polyphenols Inhibit r-Amylase in vitro: Identifying Active Components in Rowanberry and Raspberry." Journal of Agricultural and Food Chemistry 59 (6): 2324-31. doi: 10.1021/jf1045359.

[29] Agama-Acevedo, E., Islas-Hernández, J. J., Pacheco-Vargas, G., Osorio-Díaz, P., and Bello-Pérez, L. A. 2012. "Starch Digestibility and Glycemic Index of Cookies Partially Substituted with Unripe Banana Flour." LWT-Food Science and Technology 46: 177-82. 